\title{
Correcting for Density and Viscosity of Incompressible Fluids in Float-Type Flowmeters
}

\author{
Montgomery R. Shafer, Ernest F. Fiock, Harry L. Bovey, and Ross B. Van Lone
}

\begin{abstract}
The theory of the flow of incompressible fluids through float-type flowmeters is developed by the methods of dimensional analysis. The relations thus derived have been verified experimentally for the specific cases of five flowmeter tubes with 11 liquid hydrocarbons of different physical properties. Parameters that are suggested to describe the performance of any float-type flowmeter may be evaluated by measuring the float density and the mass rate of flow of fluids of known density and viscosity. Procedures are described whereby, after calibration of a metering tube with a few fluids of known physical properties, accurate corrections may be calculated for any fluid whose properties lie within the range embraced by the calibration fluids. Application of the proposed method of calibration and correction to the five metering tubes studied gave corrected values of flow that were always within one-quarter percent of the true values of flow.
\end{abstract}

\section{Introduction}

In the course of a program of research on the metering of fuels to aircraft engines, conducted under sponsorship of the Bureau of Aeronautics, the effects of the physical properties of the fluid upon metering devices have been studied extensively. Those results that pertain to the basic instrument used in establishing actual flow rates are considered of sufficient general interest to warrant separate presentation here.

Float-type flowmeters are convenient for flow testing various fuel metering accessories of both reciprocating and jet engines because they indicate flow rate directly. In such applications there is a growing demand for meters that can be used with various liquids and for increased accuracy under test conditions in which the density and viscosity of the test liquid may change with time from such causes as evaporation of light ends, admixture with heavier hydrocarbons, or inadequate control of temperature.

The word fluid appears frequently throughout this paper, although only liquid hydrocarbons were used in the experiments. This choice of terms was made for two reasons. First, the liquid used in testing the metering accessories of engines is referred to almost universally as the test fluid; and second, the results of the present study are believed to apply also to the metering of gases, provided the pressure drop at the float is negligible with respect to the absolute static pressure.

The flowmeter under consideration is of the variable-area, constant-pressure-drop type frequently referred to as a Rotameter. In such an instrument the metering takes place at an opening between a movable float and a surrounding tube so shaped that the metering area increases as the float rises. Tapered tubes of circular cross section and cylindrical tubes with tapered flutes have been used with greatest success. The instrument used in the present study was of the latter type.

Most published discussions of float-type flowmeters
[1 to 5$]^{1}$ have been concerned primarily with the basic theory and with mechanical means for reducing the sensitivity to density and viscosity of the fluid metered. The theory involves a dimensionless coefficient, analogous to the coefficient of discharge of an orifice but more difficult to evaluate and apply, since the metering area and the upstream and downstream flow conditions change with float position.

By choosing approximate values of the coefficient, the theory may be applied in designing metering tubes to have desired ranges when used with specified fluids. Due partly to lack of knowledge of the coefficient and partly to manufacturing tolerances, it has been found desirable to calibrate each meter with the same fluid later to be metered. It has not been feasible to calculate accurately the corrections that are necessary when the fluid metered has properties differing from those of the calibration fluid.

The present paper describes a method whereby, if any float-type flowmeter is calibrated with a limited number of fluids having different densities and viscosities, accurate values of the actual flow rate of any fluid having properties in the ranges of the calibration fluids can be calculated. A meter so calibrated might have a linear scale, in which case the results could be expressed in the form of calibration curves; or it might have a scale indicating the mass rate of flow of some specific fluid, with correction curves applicable to fluids having different properties. The meter thus becomes a more versatile instrument, since it can be used for accurate measurement of the actual flow rates of fluids embracing a considerable range of physical properties, without an individual calibration for each fluid.

The scale of the meter used in the present work reads directly in pounds per hour of fluid of specified density and viscosity, since it is common practice to express the rate of flow of fuel to an aircraft engine in this way. It is likewise common practice to express density and absolute viscosity in grams per cubic centimeter and in centipoises, respectively.

\footnotetext{
Figures in brackets indicate the literature references at the end of this paper.
} 
These units are used throughout this paper, despite the fact that the employment of mixed systems is objectionable in principle. Since numerical values of conversion factors are not required for present purposes, no confusion can arise from adherence to units with which the user is most familiar.

\section{Description of the Flowmeter}

The instrument used in this study is one of a lot purchased by the Navy in 1944 for use on Stromberg aircraft carburetor flow benches. It has seven tubes connected in series, so that when the range of one is exceeded, the next automatically meters the flow, in the range from 5 to $4,000 \mathrm{lb}$ of naphtha per hour. Either the first four or the first six tubes may be bypassed by means of two valves to reduce the drop in pressure, which would otherwise occur within the instrument at high flow rates.

Each cylindrical glass tube has four tapered flutes, symmetrically spaced and parallel to its axis. These flutes were so designed that indicated values of flow can be observed with the same percentage accuracy throughout the entire range of the meter. Within each tube is a spool-shaped float of stainless steel having a density of $7.589 \mathrm{~g} / \mathrm{cm}^{3}$.

The meter was calibrated at the factory with a hydrocarbon having a density of $0.733 \pm 0.002 \mathrm{~g} / \mathrm{cm}^{3}$ and a viscosity of $0.544 \pm 0.011$ centipoise, and from these data a scale in pounds per hour was ruled for each tube. Since the guaranteed accuracy was \pm 1 percent, errors up to this magnitude are to be expected in the original scales. As will be seen later, these errors in the original calibration and in the ruling of the scales therefrom introduce some complications in the present effort to obtain values of flow that are accurate to within a few tenths of 1 percent. However, this difficulty can be avoided in other instruments by specifying the accuracy of calibration and scaling that is desired.

\section{Description of the Test Fluids}

For practical reasons the properties of the fluids used in this investigation were restricted to the ranges of interest in testing aircraft engines and their fuel accessories. In all, 11 different liquid hydrocarbons, ranging in density from 0.68 to $0.80 \mathrm{~g} / \mathrm{cm}^{3}$ and in viscosity from 0.39 to 1.83 centipoises, were used. The pertinent properties of each are given in table 1. Fluids 2, 3, 4, 8, and 9 were furnished by the Phillips Petroleum Co., and fluid 10 was supplied by the Anderson-Prichard Oil Corp. The cooperation of these firms is hereby gratefully acknowledged.

TABLE 1. Properties of the test fluids

\begin{tabular}{|c|c|c|c|c|}
\hline $\begin{array}{l}\text { Test } \\
\text { fluid } \\
\text { No. }\end{array}$ & Description & $\begin{array}{l}\text { Test tem- } \\
\text { perature }\end{array}$ & $\begin{array}{c}\text { Density, } \\
\rho\end{array}$ & $\begin{array}{c}\text { Absolute } \\
\text { viscosity, } \\
\mu\end{array}$ \\
\hline $\begin{array}{r}1 \\
2 \\
3 \\
4 \\
\\
5 \\
6 \\
7 \\
8 \\
9 \\
10 \\
11\end{array}$ & $\begin{array}{l}\text { Navy test bench fluid (used) } \\
\text { Soltrol-100 a } \\
\text { Commercial isooctanes a } \\
60 \% \text { soltr ol+40\% is o o c- } \\
\text { tanes. }{ }^{\mathrm{a}} \\
\text { Varsol. } \\
\text { Varsol+hydraulic oil (I) } \\
\text { Varsol+hydraulic oil (II) } \\
\text { ASTM } n \text {-heptane a } \\
\text { Commercial } n \text {-heptane } \\
\text { Apco-467 b } \\
\text { Kerosine }\end{array}$ & $\begin{array}{l}{ }^{\circ} \mathrm{F} \\
73 \\
75 \\
70 \\
73 \\
\\
83.5 \\
77 \\
77 \\
80 \\
80 \\
80 \\
77\end{array}$ & $\begin{array}{l}\mathrm{g} / \mathrm{cm}^{3} \\
0.736 \\
.742 \\
.742 \\
.741 \\
\\
.770 \\
.792 \\
.787 \\
.681 \\
.710 \\
.801 \\
.791\end{array}$ & $\begin{array}{c}\text { Centipoises } \\
0.538 \\
1.064 \\
0.554 \\
.793 \\
\\
.821 \\
1.278 \\
1.135 \\
0.386 \\
.439 \\
1.827 \\
1.661\end{array}$ \\
\hline
\end{tabular}

a Supplied by courtesy of the Phillips Petroleum Co.

b Supplied by courtesy of the Anderson-Prichard Oil Corp.

\section{Experimental Procedure}

The two smallest tubes of the flowmeter, covering the range from 5 to $45 \mathrm{lb} / \mathrm{hr}$, were not used because the accuracy with which the actual flows could be measured at these low rates was not sufficiently high with available equipment. In each of the remaining five tubes, actual flow rates were determined with all test fluids at positions of the float near the

TABLE 2. Summary of experimental results

\begin{tabular}{|c|c|c|c|c|c|c|c|c|c|c|c|c|}
\hline \multirow{2}{*}{ Tube } & \multirow{2}{*}{$\begin{array}{l}\text { Indicated } \\
\text { flow, } M_{i}\end{array}$} & \multicolumn{11}{|c|}{ Actual flow, $M,(\mathrm{lb} / \mathrm{hr})$ of test fluid number- } \\
\hline & & 1 & 2 & 3 & 4 & 5 & 6 & 7 & 8 & 9 & 10 & 11 \\
\hline $\begin{array}{l}3 \\
3 \\
3\end{array}$ & $\begin{array}{r}l b / h r \\
55 \\
85 \\
120\end{array}$ & $\begin{array}{l}54.72 \\
85.10 \\
120.2\end{array}$ & $\begin{array}{r}49.54 \\
79.27 \\
114.2\end{array}$ & $\begin{array}{c}54.52 \\
81.86 \\
120.0\end{array}$ & $\begin{array}{r}52.12 \\
82.07 \\
117.0\end{array}$ & $\begin{array}{c}52.99 \\
83.58 \\
118.9\end{array}$ & $\begin{array}{l}49.81 \\
80.25 \\
116.2\end{array}$ & $\begin{array}{r}50.75 \\
81.30 \\
117.2\end{array}$ & $\begin{array}{r}54.88 \\
84.34 \\
117.7\end{array}$ & $\begin{array}{r}55.06 \\
85.29 \\
119.8\end{array}$ & $\begin{array}{l}46.15 \\
77.48 \\
113.7\end{array}$ & $\begin{array}{l}47.78 \\
78.30 \\
113.5\end{array}$ \\
\hline 4 & 140 & & & & & 140.0 & & & & 139. 9 & 133.8 & \\
\hline $\begin{array}{l}4 \\
4\end{array}$ & $\begin{array}{l}160 \\
180\end{array}$ & 160.4 & 154. 2 & 160. 2 & 157.8 & $\begin{array}{l}159.9 \\
180.9\end{array}$ & 157. 6 & 158. 6 & 157.3 & $\begin{array}{l}159.7 \\
180.2\end{array}$ & $\begin{array}{l}153.9 \\
174.9\end{array}$ & 155.1 \\
\hline 4 & $\begin{array}{l}210 \\
260\end{array}$ & 211. 7 & 204.1 & 211.6 & 208.3 & 211. 7 & 208.7 & 209.8 & 206.8 & 210.3 & 205.3 & 206.0 \\
\hline $\begin{array}{l}4 \\
4\end{array}$ & $\begin{array}{l}310 \\
340\end{array}$ & 309.9 & 300.3 & 309.7 & 305.7 & $\begin{array}{l}310.8 \\
341.7\end{array}$ & 308.1 & 309.1 & 303.2 & $\begin{array}{l}307.9 \\
338.3\end{array}$ & $\begin{array}{l}302.5 \\
332.3\end{array}$ & 303.1 \\
\hline 5 & 400 & 401.8 & 389.0 & 402.5 & 395.9 & 403.0 & 398.0 & 399.8 & 391.2 & 398.3 & 391.0 & 391.3 \\
\hline 5 & 520 & 522.9 & 507.8 & 523.8 & 515.0 & 523.7 & 520.1 & 521. 2 & 508.6 & 517.5 & 512.4 & 513.8 \\
\hline 5 & 700 & 701.9 & 686.2 & 703. 3 & 694.7 & 706.9 & 703.9 & 705.2 & 682.4 & 693.6 & 696.8 & 697.4 \\
\hline 6 & 900 & 902.5 & 886.3 & 905.1 & 898.1 & 912.5 & 907.1 & 909. 2 & 880.6 & 893.9 & 894. 2 & 896.7 \\
\hline 6 & 1200 & 1208 & 1188 & 1211 & 1200 & 1221 & 1214 & 1219 & 1178 & 1197 & 1201 & 1202 \\
\hline 6 & 1600 & 1606 & 1578 & 1609 & 1594 & 1621 & 1614 & 1620 & 1570 & 1597 & 1599 & 1601 \\
\hline 7 & 2000 & 2002 & 1962 & 2007 & 1989 & 2020 & 2004 & 2013 & 1947 & 1984 & 1979 & 1980 \\
\hline 7 & 2600 & 2601 & 2558 & 2608 & 2588 & 2627 & 2621 & 2624 & 2522 & 2572 & 2596 & 2593 \\
\hline 7 & 3400 & 3395 & 3346 & 3408 & - & -...... & 3421 & 3433 & 3291 & 3352 & 3396 & 3390 \\
\hline
\end{tabular}


bottom, center, and top of the tube. Tube 4 was calibrated in considerably greater detail, including four additional float positions with three test fluids, in addition to a reference calibration at intervals of $1 \mathrm{~cm}$. Each measurement was repeated at least twice, and examination of the data leads to the belief that the error in an individual observation seldom exceeded 0.25 percent. The temperature of the fluid entering the meter was controlled to within $\pm 1 \mathrm{deg}$ $\mathrm{F}$ of the values listed in table 1 under test temperature.

Three sets of equipment were used for determining actual flow rates. In earlier work with fluids 1 through 5, when these left the meter at rates between 50 and $320 \mathrm{lb} / \mathrm{hr}$, they were directed over a weir into volumetric flasks. Time, volume, and density were measured for each sample. Larger flows were determined by weighing and manual timing. In later work with fluids 6 through 11, a gravimetric calibrating stand with automatic timing was used throughout the entire flow range.

Densities of the test fluids were obtained from accurate hydrometer readings and the data of NBS Circular 410; their viscosities were determined by R. C. Hardy of this Bureau, whose assistance is hereby acknowledged.

The average results of all flow measurements are given in tables 2 and 3 .

TABLE 3. Results of reference calibration of tube 4

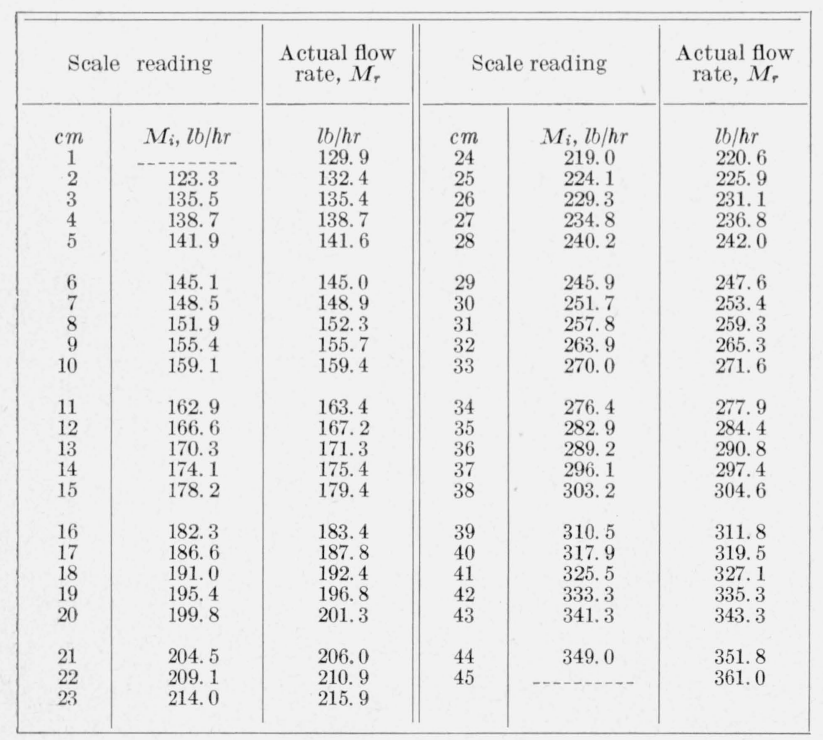

\section{Analytical Considerations}

The problems of interest in this study may be stated as follows. It is desired to consider those quantities that affect the performance of float-type flowmeters under steady flow conditions; to derive expressions relating these quantities; to check these relations experimentally; and to establish the limitations that apply to the final solutions. It is desired also to determine the effects of density and viscosity of the fluid upon the performance of a flowmeter, and to develop procedures whereby, after calibration with a few fluids of known physical properties, accurate corrections can be calculated and applied when other fluids are used.

Previous investigators have developed relations pertaining to the performance of these meters by deriving expressions based upon Bernoulli's equation, Torricelli's theorem, and the laws of resistance to flow. Although most of these derivations are sound, certain important limitations to their practical application have been overlooked at times. The method of dimensional analysis has been chosen from among the various methods by which the theory of float-type flowmeters could be presented. This method does not in itself provide a complete solution. Rather, it yields functional relations that become explicit only when combined with appropriate experimental data. Equations derived in this manner may then be used to predict and explain the effects of the various quantities upon the over-all performance of the meter.

\subsection{Theory}

Consider the float-type flowmeter shown schematically in figure 1, consisting of a vertical tapered tube, the area of which increases from bottom to top, through which a fluid of density $\rho$ and viscosity $\mu$ is flowing upward at a constant mass rate, $M$. Within the tube is an object that is free to move in the vertical direction and that may be called a float, although its density, $\rho_{s}$, is greater than $\rho$. The exact configurations of the tube and float need not be specified. Thus the consideration will apply to a variety of shapes, including tubes that are fluted, beaded and circular, and floats that are shaped like plumb bobs, spools, and disks. All of these have found application in practical flowmeters.

As a first step, it is necessary to select those quantities that may affect the drag or resistance force, $R$, acting between the flowing fluid and the stationary float. Experience indicates that $R$ may be affected by the velocity, density, viscosity, and compressibility of the fluid and by the various geometrical dimensions pertaining to the configuration of the tube and float and to the orientation and position of the float. Among these dimensions, one may be selected as a characteristic length, $D$, designating the size of the meter, and all other lengths may be expressed in terms of this characteristic length as the dimensionless ratios, $r_{1}, r_{2} \ldots \ldots r_{i}$. Practically, it is simpler to use the mass flow rate, $M$, through the tube than to express the rate of flow in terms of velocity, since $M$ is measured directly and questions as to what velocity is under consideration are avoided.

The assumption is made here that the fluid is incompressible, since primary interest here is in liquids, and since the derivation is simplified by omitting the effects of compressibility. This does not mean that the results are never applicable to the flow of gases, but rather that the range of applicability is limited to those cases in which the fluid undergoes a 


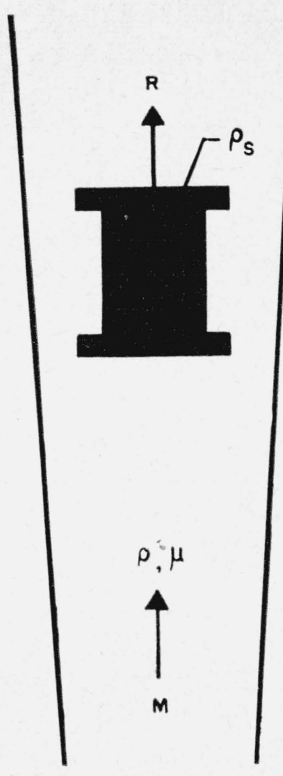

Figure 1. Schematic sketch of a float-type flowmeter.

negligible change in density as it passes the float. In other words, the analysis does apply to gases, provided that the drop in pressure across the float is only a small fraction of the absolute pressure.

Subject to this limitation, and under the assumption that only those factors discussed above contribute significantly to the drag force, their interdependence can be expressed in the form

$$
F\left(R, M, \rho, \mu, D, r_{1}, r_{2}, \ldots . \quad r_{i}\right)=0,
$$

where $F$ denotes "function of."

This equation contains five dimensional quantities and an unspecified number, $i$, of dimensionless length ratios. The dimensional quantities involved can be expressed in terms of three fundamental physical dimensions; mass $(m)$, length $(l)$, and time $(t)$. In accordance with Buckingham's $\mathrm{Pi}$ theorem $[6,7]$ eq 1 can be expressed in terms of $(i+5)-3=i+2$ dimensionless quantities. Of these, $i$ are merely length ratios, $r_{i}$, which define the shape of the meter. Thus eq 1 may be written

$$
f\left(\Pi_{1}, \Pi_{2}, r_{1}, r_{2}, \ldots . \quad r_{i}\right)=0 .
$$

Various methods can be used to form the dimensionless variables $\Pi_{1}$ and $\Pi_{2}$, which contain only the physical quantities $R, M, \rho, \mu$, and $D$. One procedure is to select any three of the latter that are independent, that is, no one of which can be formed merely by combining the other two in any way, and to associate these three in turn with each of the other two quantities so as to obtain the two dimensionless variables. To this end it is necessary to recall that the dimensions are as follows: $[R]=\left[\mathrm{mlt}^{-2}\right]$; $[M]=\left[m t^{-1}\right] ;[\rho]=\left[m l^{-3}\right] ;[\mu]=\left[m l^{-1} t^{-1}\right] ;$ and $[D]=[l]$.

Since the primary interest is in the effects of viscosity upon the mass rate of flow, it seemed desirable to derive $\Pi_{1}$ and $\Pi_{2}$ in such a way that one and only one would contain $M$, while the other alone would contain $\mu$. This left $R, \rho$, and $D$ as the three quantities that may be involved in both $\Pi_{1}$ and $\Pi_{2}$. On this basis the quantities were arranged in the form of quotients such that the physical dimensions cancelled, giving the following: $\Pi_{1}=M / D \sqrt{R_{\rho}}$; and $\Pi_{2}=\mu / \sqrt{R \rho}$.

Substitution of these values in eq 2 gives

$$
\text { or } \begin{gathered}
f\left(M / D \sqrt{R_{\rho}}, \quad \mu / \sqrt{R \rho}, r_{1}, r_{2}, \ldots . \quad r_{1}\right)=0, \\
M / D \sqrt{R \rho}=\phi\left(\mu / \sqrt{R \rho}, r_{1}, r_{2}, \ldots . \quad r_{1}\right) .
\end{gathered}
$$

Subject only to the aforementioned limitation as to compressibility, eq 4 should hold for all float-type flowmeters, regardless of the configurations of the parts or of the densities and viscosities of the fluids. The function $\phi$ may have an infinite number of forms depending on the configurations of the various parts of the meters, that is upon the $r_{i}$ ratios. As these ratios may vary in countless ways from meter to meter, it is concluded that no single form of $\phi$, and therefore no single equation, will represent the performance of flowmeters of different shapes. Even along a single metering tube with a given float, the shape factors that influence the motion of the fluid as it passes the float do not remain constant. Thus it is also concluded that no single form of $\phi$, and therefore no single equation, can be expected to represent accurately the performance throughout the length of a single flowmeter tube.

However, if the consideration be restricted to a single float shape at one given float position in a particular metering tube, eq 4 reduces to

$$
M / D \sqrt{R \rho}=\phi(\mu / \sqrt{R \rho}) .
$$

As the stationary float is unrestrained in the vertical direction, the drag force must exactly balance the force of gravity. Thus

$$
R=g v\left(\rho_{s}-\rho\right),
$$

in which $g$ and $v$ are the acceleration of gravity and the volume of the float, respectively.

Substitution of this value of $R$ in eq 5 gives

or

$$
M / D \sqrt{g v\left(\rho_{s}-\rho\right) \rho}=\phi\left(\mu / \sqrt{g v\left(\rho_{s}-\rho\right) \rho}\right),
$$

$$
M / X=\phi_{1}(\mu / X),
$$

in which $X$ is used to replace the quantity $\sqrt{\left(\rho_{s}-\rho\right) \rho}$. The quantities $D, g$, and $v$ are constant for any given float, so they may be omitted and their effects absorbed in the new function $\phi_{1}$.

For reasons that will be appreciated later, it is convenient to express the relation of eq 5 in the form

$$
M / \mu=\phi_{2}(X / \mu) \text {. }
$$

This transformation is valid since only dimensionless quantities are being treated. Thus, referring to eq 5 , it is legitimate to multiply $M / D \sqrt{R \rho}$ by $\sqrt{R \rho} / \mu$, giving $M / D_{\mu}$ for the left-hand member, and to invert the right-hand member. Again $R$ 
is replaced by its equivalent from eq 6 , and the constant quantities $D, g$, and $v$ are omitted as before.

All quantities in the arguments of eq 8 and 9 can be measured by experiment. If the equations are correct, plots of $M / X$ versus $\mu / X$ and of $M / \mu$ versus $X / \mu$ should give smooth curves, the shapes of which constitute empirical determinations of the functions $\phi_{1}$ and $\phi_{2}$ for the selected float position.

To make a comprehensive test of these equations, the actual flow rates of 11 test liquids, varying in density from 0.68 to $0.80 \mathrm{~g} / \mathrm{cm}^{3}$ and in viscosity from 0.39 to 1.83 centipoises, were measured at three selected positions of the floats in each of five different flowmeter tubes, designated as tubes 3 through 7 of the seven-tube meter. Measurements were also made at four additional float positions in tube 4 . These experimental data are summarized in table 2 .

Each of the floats was a spool of stainless steel having a density of $7.589 \mathrm{~g} / \mathrm{cm}^{3}$. Since $X$ appears in both eq 8 and 9 , and since $\rho_{s}$ was constant, a curve of $X$ as a function of $\rho$, as shown in figure 2 , proved convenient in the reduction of the results.

Figures 3 through 7 show $M / X$ as a function of $\mu / X$ for the five metering tubes. Figure 8 shows $M / \mu$ as a function of $X / \mu$ for tube 4. Each figure applies for three or more float positions, which are designated by means of numbers on the existing scales of the meters.

In every case the experimental points for all test fluids at any one float position lie on a single curve, with no value deviating from its curve by more than the experimental error of a few tenths of one percent. Thus the validity of eq 1,8 , and 9 is demonstrated over the range of densities and viscosities studied. This means that no factors that significantly affect the flow past the float have been omitted in the dimensional analysis, that the application of the results is limited only as stated above, and that the present tests were made within these and no other limitations.

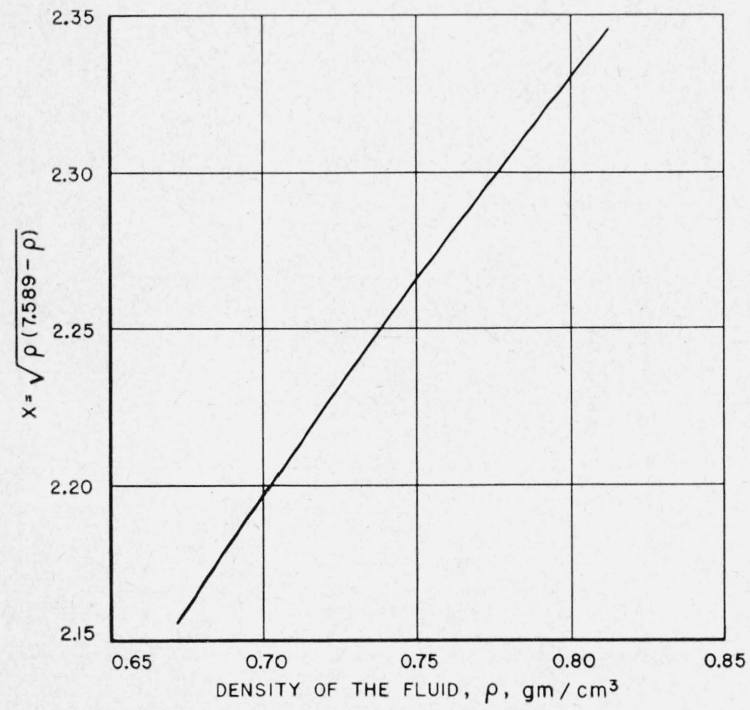
Figure 2. Relation of parameter $X$ to fluid density when
The curves shown could be used for calculating the actual flow rate of any fluid having physical properties within the ranges embraced by the test liquids, provided the float came to rest at one of the isolated

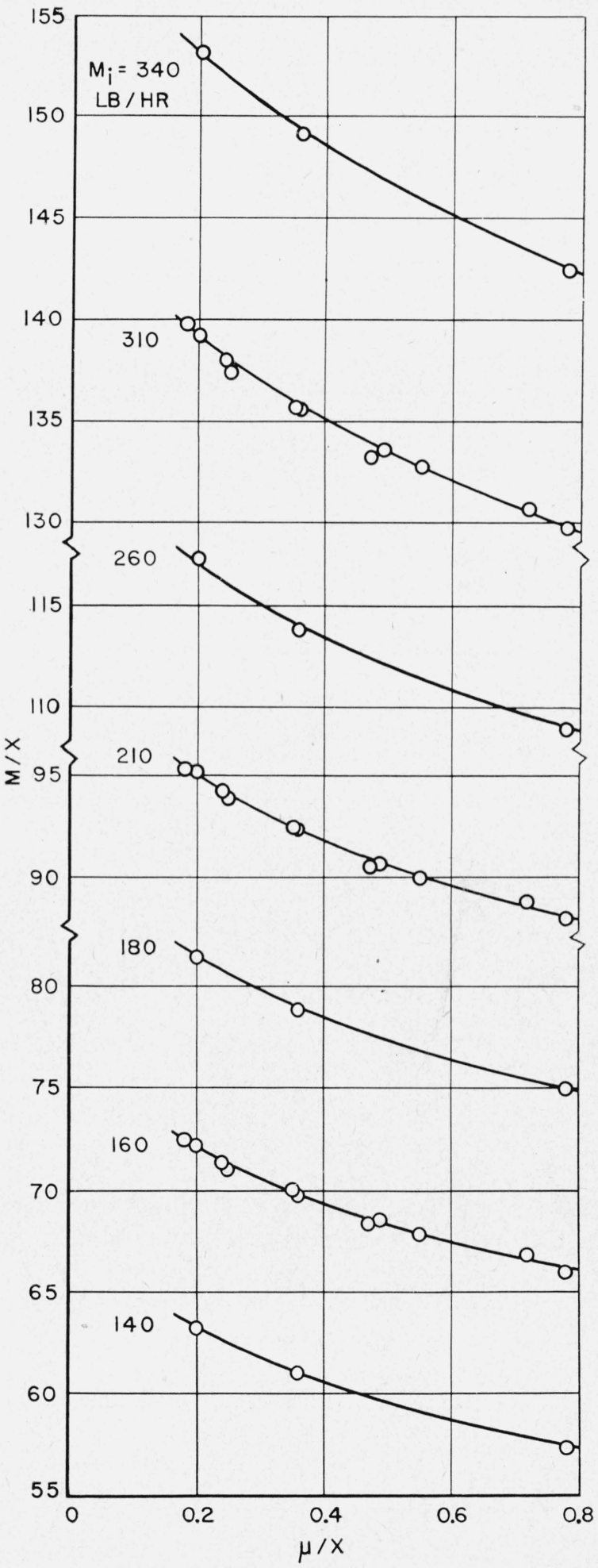

Figure 3. Plot of $M / X$ versus $\mu / X$ for tube 4 . 


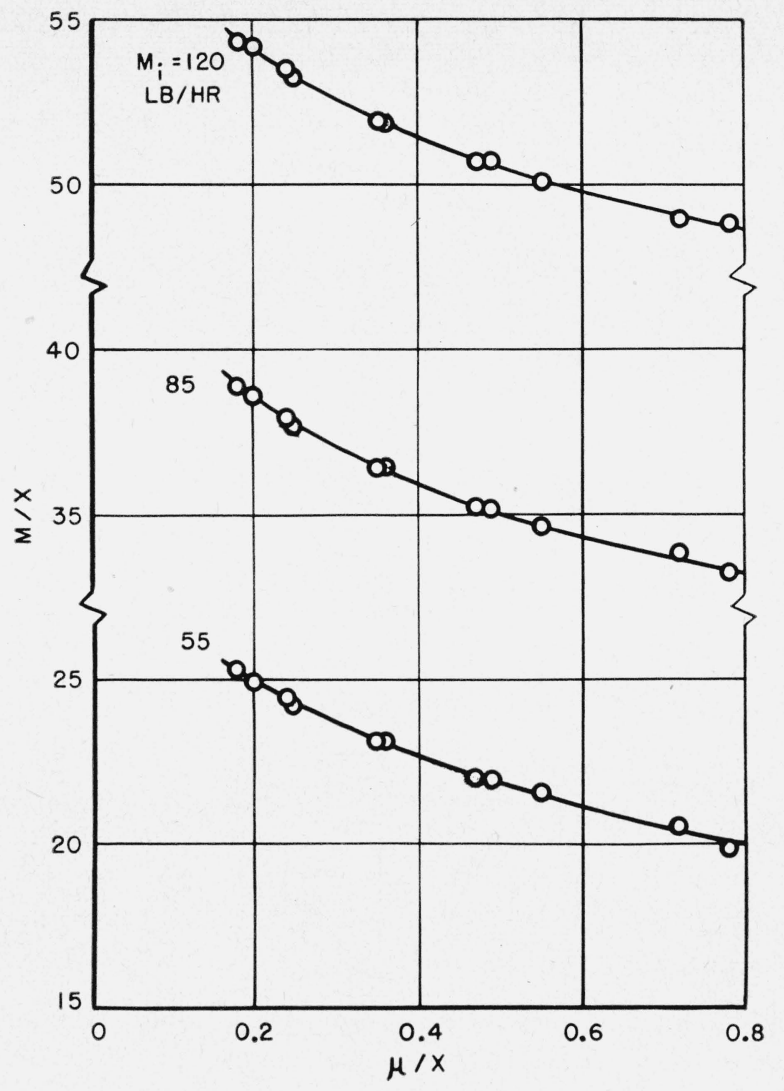

Figure 4. Plot of $M / X$ versus $\mu / X$ for tube 3 .

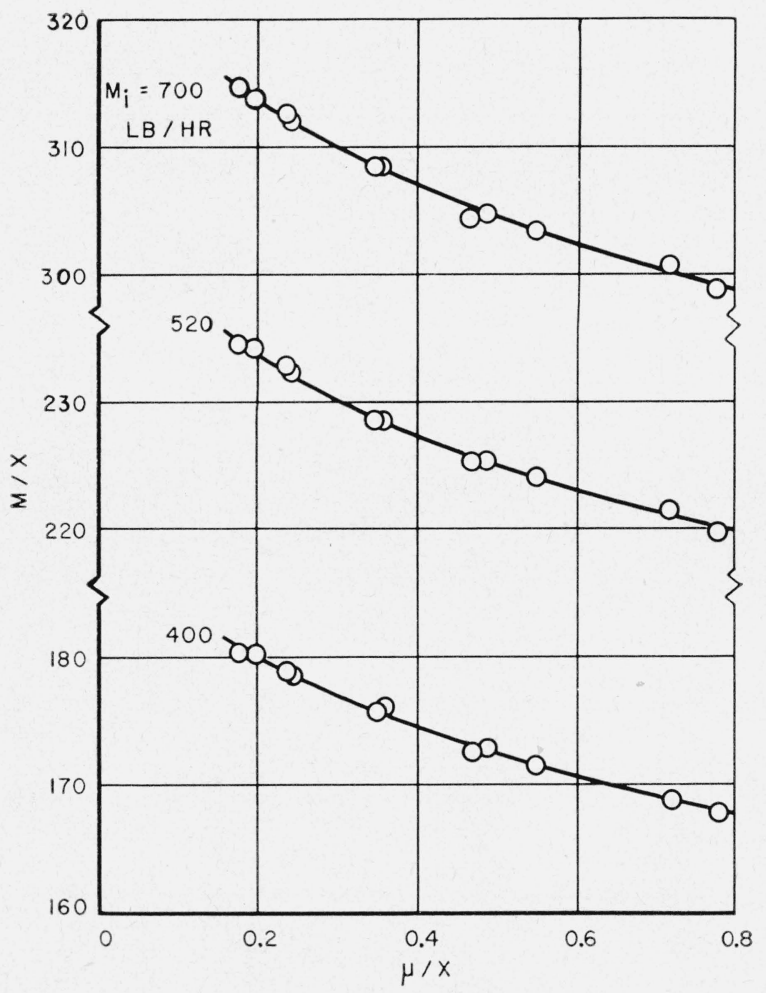

Figure 5. Plot of $M / X$ versus $\mu / X$ for tube 5.

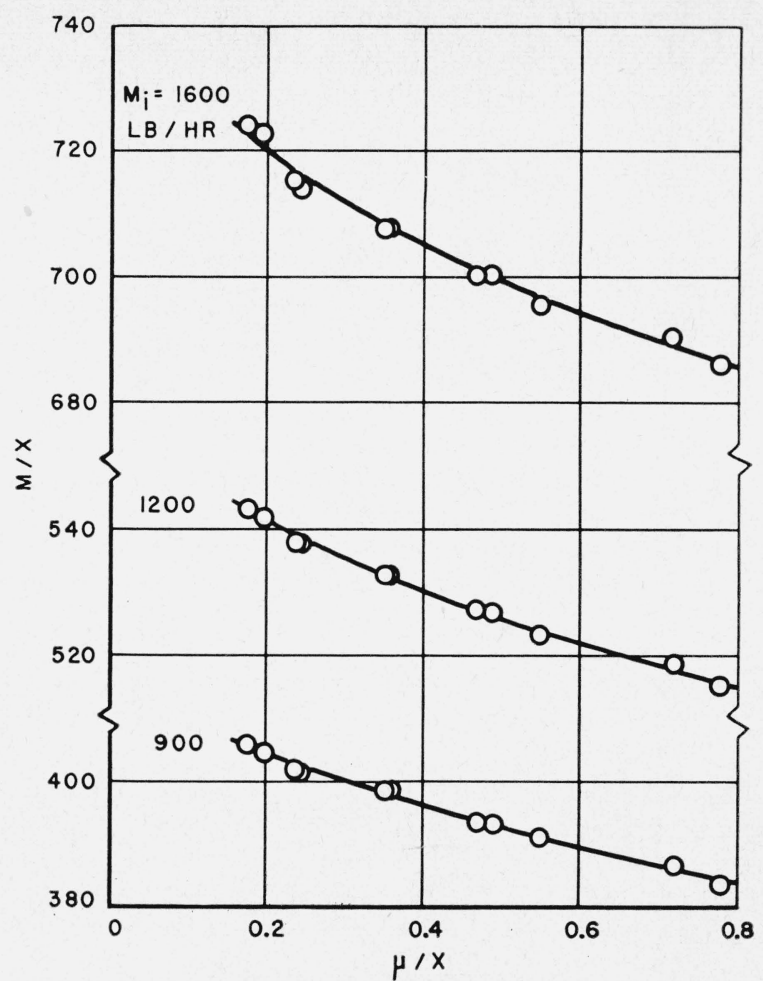

Figure 6. Plot of $M / X$ versus $\mu / X$ for tube 6 .

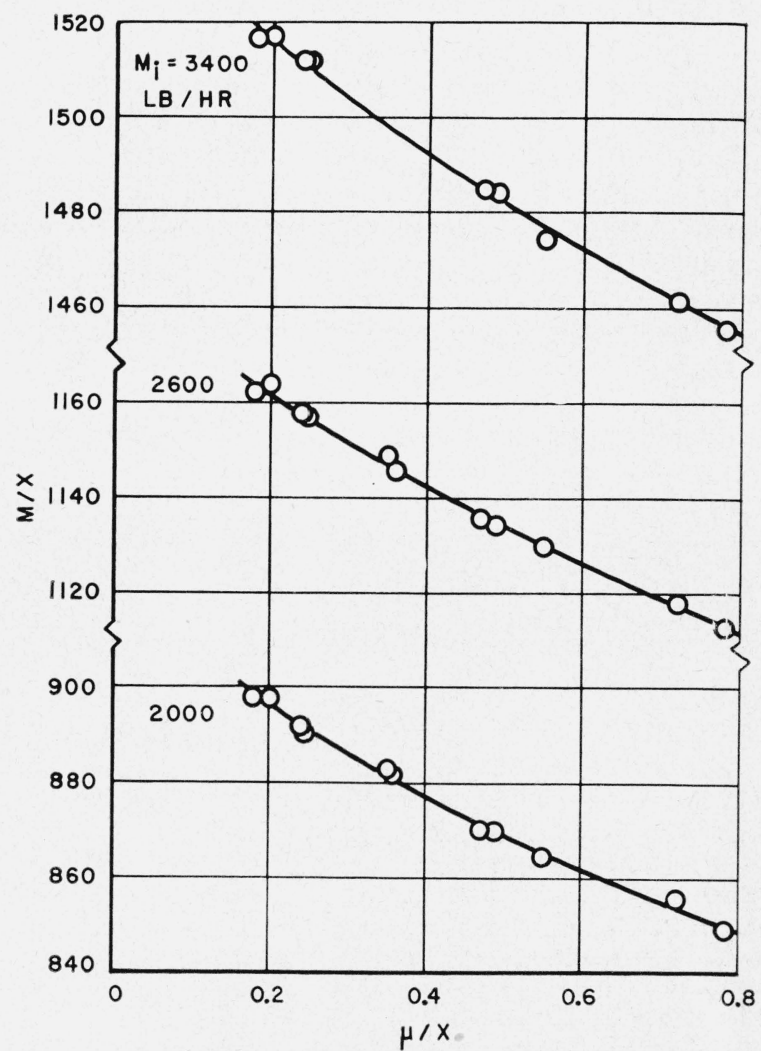

Figure 7. Plot of $M / X$ versus $\mu / X$ for tube $\gamma$. 


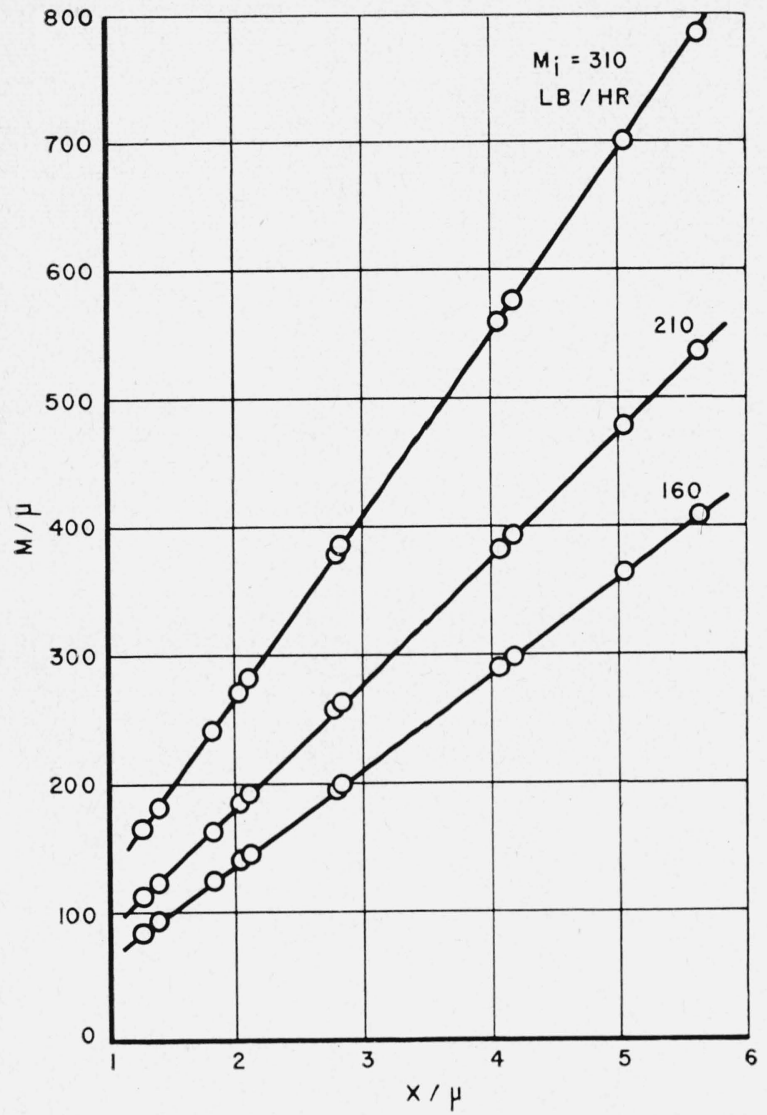

Figure 8. Plot of $M / \mu$ versus $X / \mu$ for tube 4 .

positions for which the curves apply. Since this is unlikely, a more general interpretation of the results is essential to their practical application. However, before proceeding with this, the application of the data in evaluating the separate effects of density and viscosity on meter performance will be discussed. Such information has practical importance in establishing permissible tolerances in fluid properties for any desired accuracy of metering and in evaluating changes designed to reduce the sensitivity of the meter to the physical properties of the fluid by modifying the constituent parts.

\subsection{Effects of Changes in Viscosity, Density Remaining Constant}

The effects of changes in fluid viscosity upon the performance of the meter, provided the density of the fluid remains constant, can be obtained directly from figures 3 to 7 . The curves in these figures give the empirical evaluations of the function $\phi_{1}$ of eq 8 .

If the fluid density is held constant at a value $\rho_{c}, X$ will have a corresponding constant value $X_{c}$, and eq 8 becomes

$$
M_{\rho} / X_{c}=\phi_{1}\left(\mu_{\rho} / X_{c}\right),
$$

in which the subscript $\rho$ indicates that the density is constant. Since $X_{c}$ is constant, $M_{\rho}$ varies with $\mu_{\rho}$ alone and eq 8a can be written as

$$
M_{\rho}=\phi_{1}\left(\mu_{\rho}\right) .
$$

The functions $\phi_{1}$ of eq $8,8 \mathrm{a}$, and $8 \mathrm{~b}$ are identical, and for any particular float position the form is given by the appropriate curve in figures 3 through 7 .

In order to show how $M_{\rho}$ varies with $\mu_{\rho}$, any arbitrary value $\rho_{c}$ may be selected. Here the value $\rho_{c}=0.750 \mathrm{~g} / \mathrm{cm}^{3}$ is used. Compute the corresponding value of $X_{c}$, and for assumed values of $\mu_{\rho}$ over the range of interest, compute values of the ratio $\mu_{\rho} / X_{c}$. Read the corresponding values of $M_{\rho} / X_{c}$ from one of the curves of figures 3 through 7 , and finally compute $M_{\rho}=\left(M_{\rho} / X_{c}\right) X_{c}$ for each assumed value of $\mu_{\rho}$.

Typical results obtained in this way, applicable specifically to three float positions in tube 4 , are shown as curves of $M_{\rho}$ versus $\mu_{\rho}$ in figure 9 . If the

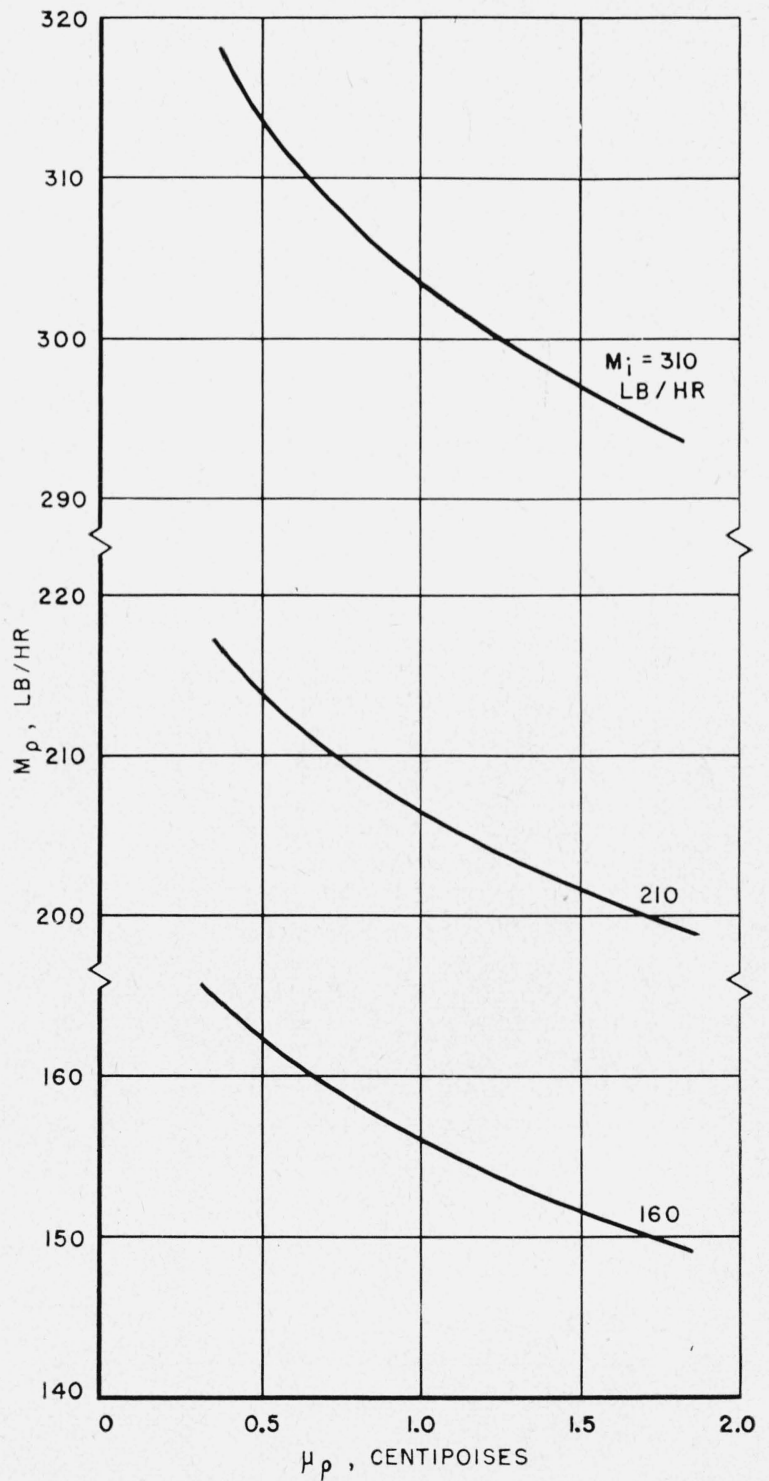

Figure 9. Effects of viscosity upon the flow rate at certain float positions in tube 4 , when $\rho_{c}=0.75 \mathrm{~g} / \mathrm{cm}^{3}$ and $\rho_{s}=7.589 \mathrm{~g} / \mathrm{cm}^{3}$. 
instrument were completely insensitive to changes in viscosity, the curves in this figure would be horizontal straight lines.

The significance of the date of figure 9 can be illustrated by a numerical example. Suppose that two fluids having a density of $0.750 \mathrm{~g} / \mathrm{cm}^{3}$ were used as follows. The meter was calibrated with fluid A, having a viscosity of 0.4 centipoise, and later fluid $B$ having a viscosity of 1.8 centipoises was metered. If no viscosity correction is applied, the observed flow rate of fluid $B$ will be approximately 8 percent too high over the entire length of the metering tube. Due to the large difference in viscosity that was assumed, this figure represents a maximum that would seldom be approached in conventional applications.

\subsection{Effects of Changes in Density, Viscosity Remaining Constant}

Equation 9 and figure 8 may be used to show the effects of changes in density when the viscosity remains constant. Using the same conventions and reasoning as before, eq 9 becomes

$$
M_{\mu} / \mu_{c}=\phi_{2}\left(X_{\mu} / \mu_{c}\right)=\phi_{2}\left[\sqrt{\left(\rho_{s}-\rho_{\mu}\right) \rho_{\mu}} / \mu_{c}\right]
$$

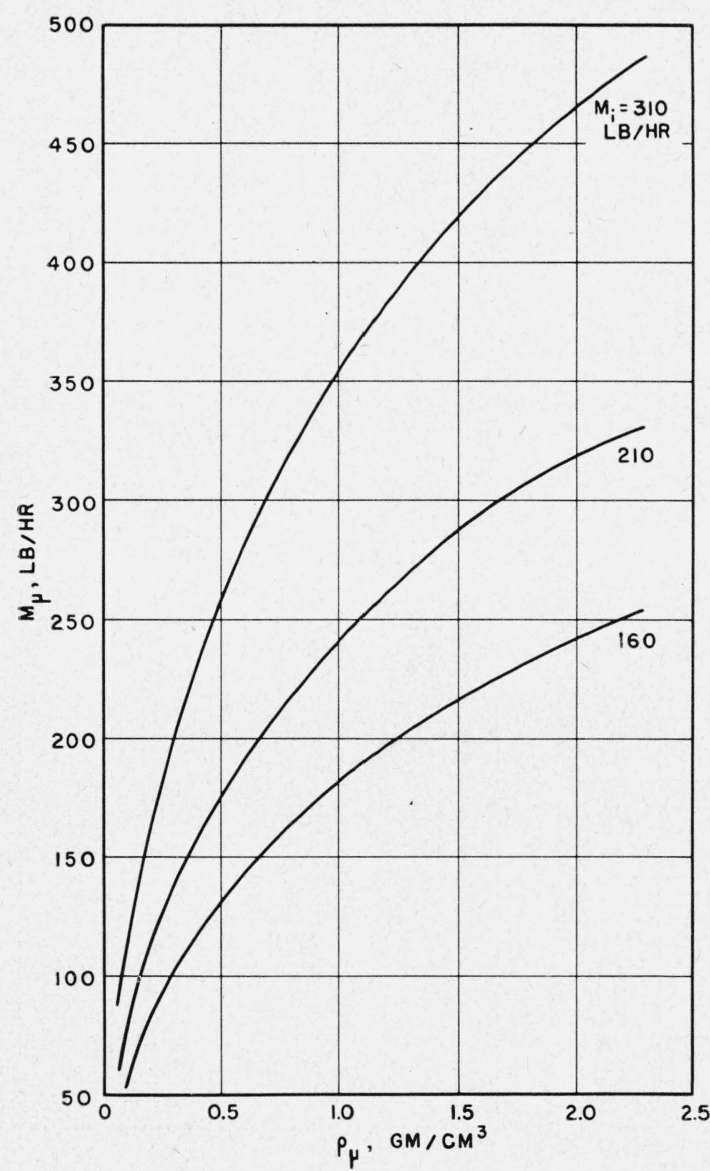

Figure 10. Effects of fluid density upon the flow rate at certain float positions in tube 4 when $\mu_{c}=0.60$ centipoise and $\rho_{s}=7.589 \mathrm{~g} / \mathrm{cm}^{3}$. or

$$
M_{\mu}=\phi_{2}^{\prime}\left(\rho_{\mu}\right),
$$

in which the function $\phi_{2}^{\prime}$ depends upon $\phi_{2}, \rho_{s}$, and the selected value of $\mu_{c}$.

Proceeding as before, an arbitrary value is assigned to $\mu_{c}$, the value 0.600 centipoise being used here. For assumed values of $\rho_{\mu}$ over the range of interest, compute $X_{\mu}=\sqrt{\left(\rho_{s}-\rho_{\mu}\right) \rho_{\mu}}$, then calculate $X_{\mu} / \mu_{c}$, read the corresponding values of $M_{\mu} / \mu_{c}$ from a curve in figure 8 , and finally compute $M_{\mu}=\left(M_{\mu} / \mu_{c}\right) \mu_{c}$ for each assumed value of $\rho_{\mu}$. Results applicable to three float positions in tube 4 are shown in figure 10. At any constant float position in tube 4 , the actual flow of two liquids having densities of 0.6 and $0.8 \mathrm{~g} / \mathrm{cm}^{3}$, each having a viscosity of 0.6 centipoise, differs by about 15 percent.

It is to be noted that the effect of increased viscosity on flow rate is in the opposite direction from that of increased density. For hydrocarbons in general, light liquids have low viscosities and heavy liquids are more viscous. Also, for such liquids a given change in temperature causes both density and viscosity to change in the same direction. Therefore, the effects of changes in these physical properties upon the metering will normally be of opposite sign. This means that the metering error due to a change in density is usually compensated in part by that from the accompanying change in viscosity.

\section{Application of the Results}

The previous analysis shows the effects of density and viscosity on the performance of the meter at selected, isolated float positions. To be generally useful, it is necessary to develop procedures whereby this analysis can be applied at all float positions along the metering tube. It is desired to evaluate corrections, preferably in the form of difference charts, applicable to either a single fluid of known density and viscosity, or to all fluids whose physical properties fall within the range embraced by the calibration fluids.

Conventional flowmeters are usually equipped with either linear scales, reading in centimeters or inches, or flow rate scales, graduated in mass flow rate units of a liquid of specified properties. Before these scale readings can be utilized in applying corrections for different fluids at any float position, a final reference calibration is required.

\subsection{Reference Calibration}

Errors that may arise from imperfections in the tube, from the factory calibration, and from the ruling and positioning of the scale can be eliminated by an accurate calibration with a single liquid whose physical properties need not be known. Since differences obtained with other fluids are reckoned from this calibration, it is termed a reference calibration.

A reference calibration of tube 4, equipped with a linear scale as well as the factory scale graduated 


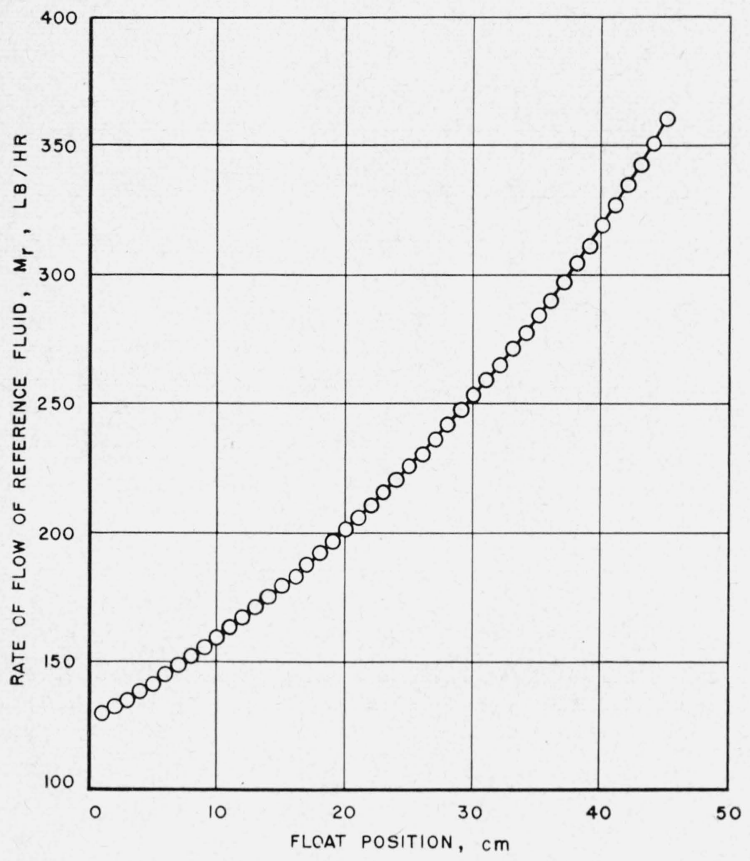

Figure 11. Reference calibration of tube 4 in terms of float position.

in pounds per hour, was made at 45 float positions, that is, at intervals of $1 \mathrm{~cm}$ on the linear scale. At each float position the actual flow rate, $M_{r}$, was determined, the linear scale was read, and the indicated flow, $M_{i}$, was observed. The results are summarized in table 3 .

For a meter with a linear scale, this calibration can be represented by the curve of figure 11, in which $M_{r}$ is shown as a function of the position of the float in centimeters above an arbitrary zero. Drawn to a large enough scale, such a curve may be used to read flow rates with an accuracy of about 0.1 percent.

For a meter graduated in terms of flow, it is convenient to express the reference calibration in the form of a difference curve such as that shown in figure 12 , which is applicable to tube 4 . In this figure the difference $M_{r}-M_{i}$ is called a composite error, $E$, as it involves both accidental errors and systemmatic differences. Actually, the density and viscosity of the reference fluid differed considerably from the corresponding properties of the fluid with which the meter was calibrated originally, so that the values of $E$ should not be confused with the smaller errors in the original calibration from which the scale was ruled.

\subsection{Combined Correction Procedure for a Single Fluid}

Suppose that a given meter is to be used with a single fluid of known density and viscosity. It is desired to devise a procedure and develop a correction chart from which the actual flow rate, $M$, of this particular fluid may be calculated accurately at any indicated flow rate, $M_{i}$.

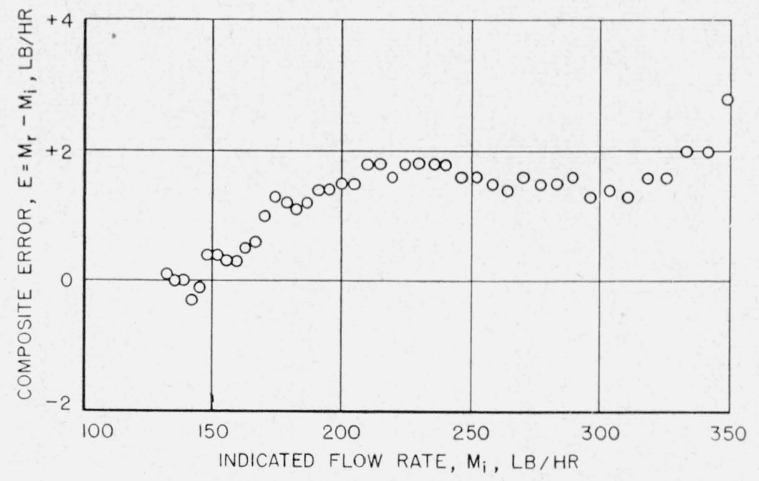

Figure 12. Composite error from the reference calibration of tube 4 .

It has been shown that two corrections must be considered, namely one for errors in the existing scale, and one for the density and viscosity of the fluid to be metered. Determination of the composite error, $E$, as illustrated in figure 12 , provides a possible means of correcting for the scale errors. From this figure any observed value of indicated flow, $M_{i}$, can be converted into the actual flow of the reference fluid by the relation $M_{r}=E+M_{i}$. Having obtained the value of $M_{r}$ at any indicated flow reading, the difference between the actual flow rate of the fluid to be metered and the actual flow rate of the reference fluid, that is, $\left(M-M_{\tau}\right)$, is due solely to effects of differences in density and viscosity of the test and reference fluids.

The actual flow rate, $M$, of the fluid being metered is the sum of the quantities $M_{r}=E+M_{i}$ and $M-M_{r}$. The value of $E$ corresponding to any observed value of $M_{i}$ can be read from figure 12 , so that $M_{r}$ is known. To calculate $M$ requires in addition a correction chart from which the quantity $M-M_{r}$ can be read. The development of such a chart will now be discussed.

For this illustration, suppose it is desired to use tube 4 of the present instrument to meter a fluid having a density of $0.745 \mathrm{~g} / \mathrm{cm}^{3}$ and a viscosity of 0.924 centipoise at the temperature prevailing in the meter.

From figure 2 the value of $X$ corresponding to $\rho=0.745$ is seen to be 2.258 . The corresponding value of $\mu / X$ for our example is $0.924 / 2.258=0.409$. These, as well as the following computations, are tabulated in table 4.

TABLE 4. Computation of $\left(M-M_{r}\right)$ in tube 4 when $\rho=0.745$ $\mathrm{g} / \mathrm{cm}^{3}$ and $\mu=0.924$ centipoise

$$
X=2.258 ; \mu / X=0.409
$$

\begin{tabular}{|c|c|c|c|c|c|c|c|}
\hline$M_{i} \mathrm{lb} / \mathrm{hr}$ & 140 & 160 & 180 & 210 & 260 & 310 & 340 \\
\hline Float position, $\mathrm{cm}$ & 4. 4 & 10. 2 & 15.4 & 22.2 & 31.4 & 39.0 & 42.8 \\
\hline$E=M_{r}-M_{i}, 1 \mathrm{~b} / \mathrm{hr}_{-}$ & -0.2 & +0.4 & +1.1 & +1.7 & +1.5 & +1.4 & +2.2 \\
\hline$M_{r}=M_{i}+E, 1 \mathrm{~b} / \mathrm{hr}_{-}$ & 139.8 & 160.4 & 181.1 & 211.7 & 261.5 & 311.4 & 342.2 \\
\hline$M / X$ & 60.6 & 69.3 & 78.4 & 91.6 & 113.2 & 134.7 & 148.2 \\
\hline$M=2.258(M / X), \mathrm{lb} / \mathrm{hr}$. & 136.8 & 156.5 & 177.0 & 206.8 & 255.6 & 304.2 & 334.6 \\
\hline$M-M_{r}, \mathrm{lb} / \mathrm{hr} \ldots$ & -3.0 & -3.9 & -4.1 & -4.9 & -5.9 & +7.2 & -7.6 \\
\hline
\end{tabular}

The first line of table 4 lists the seven float positions, that is, values of $M_{i}$, at which the calibration curves of figure 3 were determined. The same float 


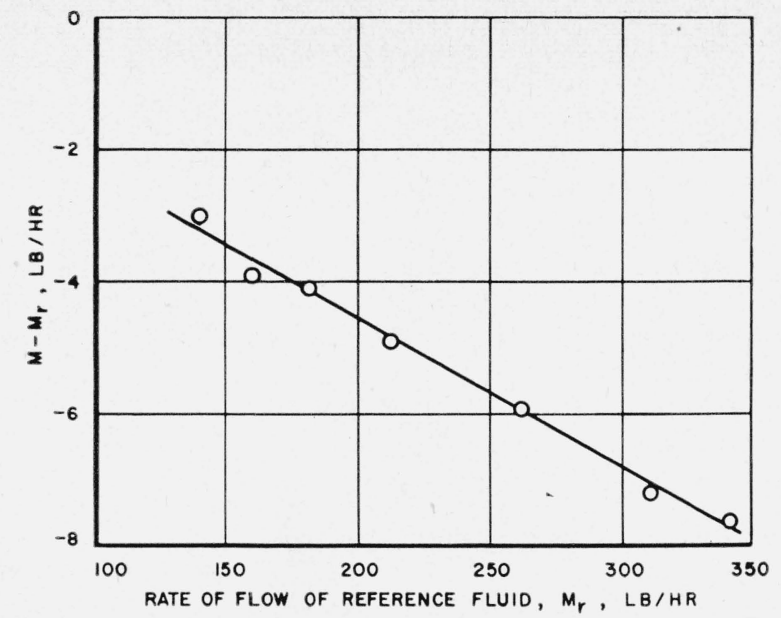

Figure 13. Correction curve for tube 4, assuming $\rho=0.745$ $\mathrm{g} / \mathrm{cm}^{3}$ and $\mu=0.924$ centipoise.

positions, as indicated on a linear scale above an arbitrary zero, are given in the next line. The appropriate values of $E$, as read from figure 12 , and the values of $M_{r}=M_{i}+E$ are listed in the next two horizontal lines.

Referring again to figure 3, the tabulated values of $M / X$ corresponding to the constant value $\mu_{i}^{\prime} X=0.409$ were read from each of the seven curves. The actual flow rates, $M$, were then obtained by multiplying each value of $M / X$ by 2.258 , that is, by the $X$ for this particular example. Having thus found seven corresponding values of $M$ and $M_{r}$, the desired correction, $M-M_{r}$ can be plotted as a function of $M_{r}$, as is done in figure 13 .

For the fluid chosen as an illustration, the corrections $\left(M-M_{r}\right)$ range from 3.0 to $7.6 \mathrm{lb} / \mathrm{hr}$, and none of the seven points deviates from the smooth curve by more than 0.2 percent. Hence the combined effect of density and viscosity is to produce regular, rather than stepwise, changes in metering over the length of the tube.

Any indicated flow reading obtained with a fluid having the selected properties may now be corrected as follows by using figures 12 and 13 . For any indicated flow reading, $M_{i}$, the corresponding value of $E$ is read from figure 12 and the value of $M_{r}=E+M_{i}$ is computed. The corresponding value of $\left(M-M_{r}\right)$ is then obtained from figure 13. Finally, the actual flow rate is obtained by adding $M_{r}$ to $M-M_{r}$.

For a meter having a linear scale, $M_{r}$ is read from figure 11 at a number of float positions, and the corresponding values of $M$ are determined by use of figure 13. A calibration curve applicable to this specific fluid may then be plotted in terms of $M$ as a function of the position of the float in centimeters.

\subsection{Combined Correction Procedure for Any Fluid}

Application of the procedure outlined above requires a correction chart or calibration curve for each fluid to be metered. If several different fluids are to be metered, a more general method of correc-

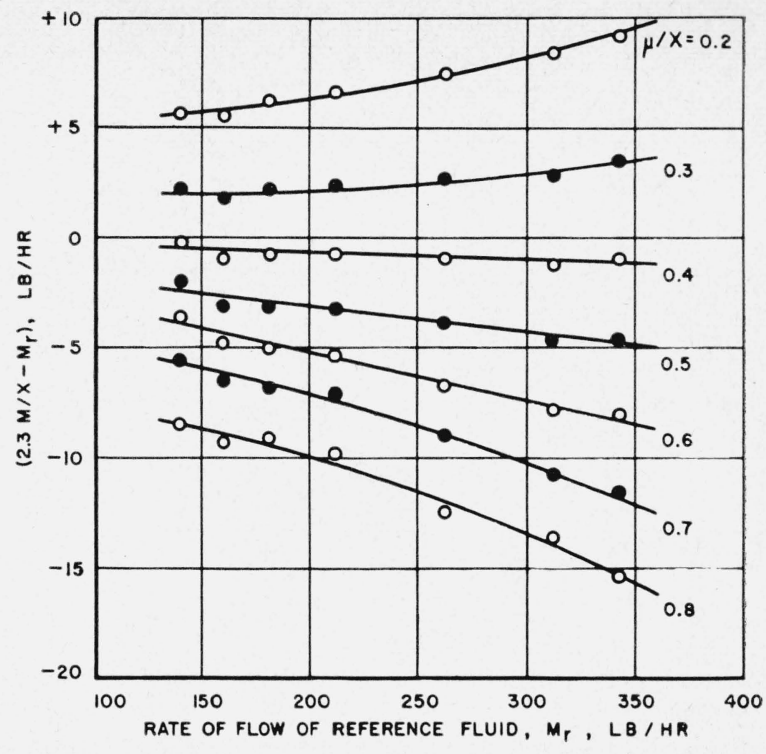

Figure 14. Generalized correction chart for table 4.

tion is desirable, that is, one which is applicable to any float position and to any fluid for which the value of $\mu / X$ lies within the range embraced by the calibration fluids.

As in the previous example, corrections for both the composite error and the properties of the fluid must be considered. The composite error may be treated as before, by converting indicated flow rates, $M_{i}$, to actual flow rates, $M_{r}$, of the reference fluid through the use of figure 12 . It is then necessary only to develop a chart to correct for differences between the densities and viscosities of the reference fluid and any other fluid that may be metered. The development of such a chart will now be discussed.

For the present consideration of a float of constant shape, regardless of its position within a single metering tube, eq 7 may be written as

$$
M / D X \sqrt{g v}=\phi(\mu / X \sqrt{g v}, r),
$$

in which the dimensionless ratio $r$ is used as an indication of the float position.

With any constant value of the parameter $\mu / X \sqrt{g v}$, the product $M / D X \sqrt{g v}$ will be a function of $r$ alone. For this particular condition it is permissible to write

$$
(M / D X \sqrt{g v})-r=\phi_{3}(r)
$$

where the form of the function $\phi_{3}$ will be different for each value of $\mu / X \sqrt{g v}$.

The dimensionless ratio $r$ has been used to define float position. As will be seen in figure 11, this can also be defined by $M_{r}$; thus, $r$ may be replaced by $M_{r}$. Also, it is useful and permissible to multiply $M / D X \sqrt{g v}$ by a dimensionless number $A$. Equation 10a may now be written as

$$
(A M / X)-M_{r}=\phi_{4}\left(M_{r}\right) .
$$


TABle 5. Computation of $\left[2.3(M / X)-M_{r}\right]$ in tube 4 at assumed values of $\mu / X$

\begin{tabular}{|c|c|c|c|c|c|c|c|c|c|c|}
\hline$M_{i}$ & & $M_{\tau}$ & $\mu / X=$ & 0.2 & 0.3 & 0.4 & 0.5 & 0.6 & 0.7 & 0.8 \\
\hline$l b / h r$ & $\mathrm{~cm}$ & $l b / h r$ & {$[M / X$ from fig. 3} & 63.20 & 61.72 & 60.70 & 59.90 & 59.20 & 58,40 & 57.10 \\
\hline 140 & 4.4 & 139.8 & $\left\{\begin{array}{l}2.3 M / X \\
2.3 M / X-M_{r-2} \\
M / X\end{array}\right.$ & $\begin{array}{c}145.4 \\
5.6 \\
72.15\end{array}$ & $\begin{array}{c}142.0 \\
2.2 \\
70.52\end{array}$ & $\begin{array}{l}139.6 \\
-0.2 \\
69.35\end{array}$ & $\begin{array}{c}137.8 \\
-2.0 \\
68.40\end{array}$ & $\begin{array}{l}136.2 \\
-3.6 \\
67.65\end{array}$ & $\begin{array}{l}134.3 \\
-5.5 \\
66.90\end{array}$ & $\begin{array}{l}\text {. } 131.3 \\
-8.5 \\
65.70\end{array}$ \\
\hline 160 & 10.2 & 160.4 & $\begin{cases}2.3 & M / X \\
2.3 & M / X-M_{r} \\
M / X\end{cases}$ & $\begin{array}{c}165.9 \\
5.5 \\
81.45\end{array}$ & $\begin{array}{c}162.2 \\
1.8 \\
79.70\end{array}$ & $\begin{array}{l}159.5 \\
-0.9 \\
78.45\end{array}$ & $\begin{array}{c}157.3 \\
-3.1 \\
77.40\end{array}$ & $\begin{array}{l}155.6 \\
-4.8 \\
76.55\end{array}$ & $\begin{array}{l}153.9 \\
-6.5 \\
75.80\end{array}$ & $\begin{array}{l}151.1 \\
-9.3 \\
74.80\end{array}$ \\
\hline 180 & 15.4 & 181.1 & $\left\{\begin{array}{l}2.3 M / X \\
2.3 M / X-M_{r-} \\
M / X\end{array}\right.$ & $\begin{array}{c}\text { 187. } 3 \\
\text { 6. } 2 \\
94.93\end{array}$ & $\begin{array}{c}183.3 \\
2.2 \\
93.10\end{array}$ & $\begin{array}{l}180.4 \\
-0.7 \\
91.73\end{array}$ & $\begin{array}{c}178.0 \\
-3.1 \\
90.62\end{array}$ & $\begin{array}{l}176.1 \\
-5.0 \\
89.72\end{array}$ & $\begin{array}{l}174.3 \\
-6.8 \\
88.95\end{array}$ & $\begin{array}{l}172.0 \\
-9.1 \\
87.80\end{array}$ \\
\hline 210 & 22.2 & 211.7 & $\left\{\begin{array}{lll}2.3 & M / X \\
2.3 & M / X-M_{r}\end{array}\right.$ & $\begin{array}{l}218.3 \\
6.6\end{array}$ & $\begin{array}{c}214.1 \\
2.4\end{array}$ & $\begin{array}{l}211.0 \\
-0.7\end{array}$ & $\begin{array}{l}208.4 \\
-3.3\end{array}$ & $\begin{array}{l}206.4 \\
-5.3\end{array}$ & $\begin{array}{l}204.6 \\
-7.1\end{array}$ & $\begin{array}{l}201.9 \\
-9.8\end{array}$ \\
\hline & & & $M / X$ & 116.9 & 114.8 & 113.3 & 112.0 & 110.8 & 109.8 & 108.6 \\
\hline 260 & 31.4 & 261.5 & $\begin{cases}2.3 & M / X \\
2.3 & M / X-M_{r}\end{cases}$ & $\begin{array}{r}268.9 \\
7.4\end{array}$ & $\begin{array}{r}264.2 \\
2.7\end{array}$ & $\begin{array}{l}260.6 \\
-0.9\end{array}$ & $\begin{array}{l}257.6 \\
-3.9\end{array}$ & $\begin{array}{l}254.8 \\
-6.7\end{array}$ & $\begin{array}{l}252.5 \\
-9.0\end{array}$ & $\begin{array}{r}249.8 \\
-12.5\end{array}$ \\
\hline & & & $M / X$ & 139.0 & $\begin{array}{r}2 . \\
136.6\end{array}$ & $\begin{array}{l}-0.9 \\
134.8\end{array}$ & $\begin{array}{l}-3.9 \\
133.4\end{array}$ & $\begin{array}{l}-6.7 \\
132.0\end{array}$ & $\begin{array}{r}-9.0 \\
130.8\end{array}$ & $\begin{array}{r}-129.5 \\
129.5\end{array}$ \\
\hline 310 & 39.0 & 311.4 & $\{2.3 M / X$ & 319.8 & 314. 2 & 310.2 & 306.8 & 303.6 & 300.7 & 297.8 \\
\hline & & & $2.3 M / X-M_{r} \ldots \ldots$ & $\begin{array}{r}8.4 \\
1528-10\end{array}$ & $\begin{array}{r}2.8 \\
50.3\end{array}$ & -1.2 & -4.6 & -7.8 & -10.7 & -13.6 \\
\hline 340 & 42.8 & 342.2 & $\int_{2.3 M}^{M} M / X$ & $\begin{array}{l}152.8 \\
351.4\end{array}$ & $\begin{array}{l}150.3 \\
345.7\end{array}$ & $\begin{array}{l}148.8 \\
341.3\end{array}$ & $\begin{array}{l}146.8 \\
337.6\end{array}$ & $\begin{array}{l}145.3 \\
334.2\end{array}$ & $\begin{array}{l}143.8 \\
330.7\end{array}$ & $\begin{array}{l}142.1 \\
326.8\end{array}$ \\
\hline & & & $2.3 M / X-M_{r}$ & 9.2 & 3.5 & -0.9 & -4.6 & -8.0 & -11.5 & -15.4 \\
\hline
\end{tabular}

Neither $D, v$, or $g$ varies for any particular float, so that they may be omitted if their effects are absorbed in the new function $\phi_{4}$.

Restating the limitations, Equation $10 \mathrm{~b}$ applies to a constant float shape, regardless of position within a single metering tube, for any constant value of $\mu / X$. By arbitrarily choosing values of $\mu / X$ in the range of interest, a family of curves of $(A M / X-$ $M_{r}$ ) versus $M_{r}$ can be obtained, as has been done in figure 14 .

Although the constant $A$ may be assigned any arbitrary value, it is desirable that the quantity $A M / X-M_{r}$ be kept small so that correction curves made therefrom can be read to a high percentage accuracy. This situation prevails when $A$ is approximately equal to the average value of $X$ for the calibration fluids, which, in the present case was 2.3 . This value was therefore used in computing table 5 , from which figure 14 is plotted.

The development of this table and figure, again applicable to tube 4 , will now be explained. Column 1 of table 5 lists the seven values of $M_{i}$ at which the calibration curves of figure 3 were determined. These same float positions, as indicated on a linear scale above an arbitrary zero, are given in column 2 . Corresponding flow rates, $M_{r}$, of the reference fluid may be obtained from either figure 11 or 12 , and are listed in column 3.

Values of $\mu / X$ from 0.2 to 0.8 , in intervals of 0.1 were chosen arbitrarily. For each of these, seven values of $M / X$ were read from the curves of figure 3 , and the quantities $2.3 \mathrm{M} / X$ and $2.3 \mathrm{M} / \mathrm{X}-\bar{M}_{r}$ were computed and tabulated. The latter values were plotted versus $M_{r}^{*}$ in figure 14 for each of the chosen, constant values of $\mu / X$. From this family of curves, used in conjunction with figure 12 when the meter has been scaled to read in terms of flow rate, any indicated value of the latter can be converted into actual flow rate, provided only that the density and viscosity of the fluid being metered are known, that calibrations such as those of figures 3 and 12 have been made, and that the properties of the fluid lie within the ranges embraced by the calibration fluids.
To illustrate the use of figure 14, assume that a. fluid having $\rho=0.740 \mathrm{~g} / \mathrm{cm}^{3}$ and $\mu=0.924$ centipoise is flowing through tube 4 at an indicated flow rate of $310 \mathrm{lb} / \mathrm{hr}$. From figure $12, E=1.4$, so that $M_{r}=$ $311.4 \mathrm{lb} / \mathrm{hr}$. From figure $2, X=2.258$. The value of $\mu / X$ is 0.409 . From figure 14 , by interpolation to $\mu / X=0.409$, at $M_{r}=311.4,2.3 M / X-M_{r}=-1.5$. The actual flow rate is

$$
\begin{aligned}
M & =\left[\left(A M / X-M_{\tau}\right)+M_{\tau}\right] X / A \\
& =(-1.5+311.4)(2.258 / 2.3)=304.2 \mathrm{lb} / \mathrm{hr} .
\end{aligned}
$$

It will be noted that this is identical with the value computed by a different method in table 4 .

A procedure has been described whereby a floattype flowmeter may be used to meter any fluid having a value of $\mu / X$ within that range embraced by those fluids used to calibrate the meter. Questions concerning the extent of the calibration and the accuracy of the procedure naturally arise. These cannot be answered explicitly, because much depends. upon the characteristics of the instrument under consideration. For a meter already calibrated and scaled, the accuracy of previous work is also involved. Still another factor that varies from meter to meter is the extent and manner in which $M / X$ changes with $\mu / X$. If, for example, the curves of figures 3 through 7 were approximately straight lines over the range of interest, calibration with three fluids would suffice. Another design might show sudden changes in the relation between $M / X$ and $\mu / X$, particularly at high values of $\mu / X$. In this case five or even more calibration fluids would be required. Since this. relation can be determined only by experiment, these curves should never be extended beyond those values of $\mu / X$ for which experimental data are available.

For the meter used in the present study it appears that calibration with 4 or 5 fluids instead of 11 would have sufficed to define the curves of figures 3 to 7 . It also seems, because of the smoothness of the curves. of figures 13 and 14, that calibration of each tube at four float positions would have been ample. Posi- 
tions close to both top and bottom of the tube should be included, because of the effects of entrance and exit flow conditions. When the flow pattern within the tube is influenced by the connections to the meter, the same connections should be used during calibration and service.

For the reference calibration yielding figures 11 and 12 , approximately one-third the number of points taken would have sufficed for a meter of this quality. However, if the tube and its scale had been crudely made, it might have been necessary to calibrate at intervals of less than $1 \mathrm{~cm}$.

\section{Summary}

The float-type flowmeter is very convenient for measuring instantaneous rates of flow. Results accurate to within a few tenths of 1 percent can be attained with the meter used in the present study, provided adequate corrections are applied for the effects of the density and viscosity of the test liquid, and for imperfections in the original calibration and scale.

Usually such meters are calibrated and scaled at the factory in mass flow rate units for a liquid of specified properties. The present work was undertaken in an effort to develop means whereby the meter need not be calibrated directly with each liquid that is to be metered. The results show that this can be accomplished for meters of the quality used in these tests by calibrating each tube initially at four positions of the float with four or five fluids having physical properties embracing the ranges of future interest. Calibration with one liquid at a greater number of float positions is also required to eliminate errors due to possible imperfections in the tube and its scale. With such calibrations available, methods are presented whereby correction charts or calibration curves applicable to all fluids having properties within the ranges of those used in the calibration may be computed.

The present analysis expresses flowmeter performance as a functional relation between the parameters $M / X$ and $\mu / X$. These parameters are developed by dimensional analysis, supplemented by experimental verification of the fact that no quantity that has a significant effect on the flow of fluid past the float of the meter has been omitted. The analysis is general, in that it applies to all kinds of float-type flowmeters, regardless of the configuration of tube or float. The derived relations apply for all imcompressible fluids and for gases under the limited condition that the drop in pressure across the float shall not be an appreciable fraction of the absolute pressure.
The analysis also indicates why previous attempts to develop theoretical equations applicable throughout the entire length of one flowmeter tube, or for more than one meter, were not markedly successful Actually it is not to be expected that a single theoreti cal equation can express accurately the performance of a single flowmeter over its entire length under all conditions likely to be encountered in service.

Experimental values of the parameters $M / X$ and $\mu / X$, obtained from calibrations with a series of fluids at selected positions of the float, are shown to be useful, not only in determining corrections that must be applied when fluids having other properties are metered, but also in evaluating the separate effects of density and viscosity on meter performance.

Most of the results presented apply specifically to tube 4 of the meter actually used in these tests. Similar results with other tubes confirm the soundness of the proposed method of correction, but do not require presentation in detail. Whereas the calibration procedure and the methods suggested for its subsequent use, as outlined here, are believed applicable to float-type flowmeters in general, it is emphasized that the numerical values quoted apply only to the specific meter used, and that the correction charts are intended as examples, and not for use with any other instrument.

The suggestions and assistance of H. N. Eaton, Chief of the Hydraulics Section, in applying the methods of dimensional analysis to the present problem are gratefully acknowledged.

\section{References}

[1] E. M. Schoenborn, Jr. and A. P. Colburn, The flow mechanism and performance of the rotameter, Trans. Am. Inst. Chem. Engr. 35, 359 (1939).

[2] J. C. Whitwell and D. S. Plumb, Correlation of rotameter flow rates, Ind. Eng. Chem. 31, 451 (1939).

[3] L. E. Stout and A. R. Rowe, A new type of fluid rate flowmeter, Trans. Amer. Inst. Chem. Engr. 34, 1 (1938).

[4] K. Fischer, S. Bleckman, and E. Lipstein, The elimination of viscosity as a factor in determining rotameter calibration, Trans. Am. Inst. Chem. Engr. 36, 857 (1940).

[5] R. C. Kintner, Visual fluid flowmeters with straightwalled tubes, Ind. Eng. Chem., Anal. Ed. 14, 261 (1942).

[6] E. Buckingham, Notes on the method of dimensions, Phil. Mag. 42, 696 (1921).

[7] E. Buckingham, On physically similar systems; illustrations of the use of dimensional equations, Phys. Rev. 4, 345 (1914).

[8] J. J. Martin, Calibration of Rotameters, Chem. Eng. Prog. 45, 338 (1949).

Washington, February 20, 1950 ; 